Karrer, P. \& Jucker, E. (1948). Carotinoide. Basel: Birkhauser.

Karrer, P., Jucker, E., Rutschmann, J. \& Steinlin, K. (1945). Helv. chim. Acta, 28, I I $46 .^{6}$

Karrer, P., Patel, D. K. \& Benz, J. (1949). Helv. chim. Acta, 32, 1938.

Karrer, P. \& Rüegger, A. (1940). Helv. chim. Acta, 23, 955.

Karrer, P., Rüegger, A. \& Geiger, A. (1938). Helv. chim. Acta, 21, 1171.

Karrer, P. \& Schwab, G. (1940). Helv. chim. Acta, 23, 578.

Karrer, P. \& Solmssen, U. (1937). Helv. chim. Acta, 20, 682.

Kemmerer, A. R. \& Fraps, G. S. (1945). F. biol. Chem. 16r, 305.

Kuhn, R. \& Brockmann, H. (1933). Ber. disch. chem. Ges. 66, I3I9.

Meunier, P. (1948). C.R. Acad. Sci., Paris, 227, 206.

Milas, N. A. (1947). Vitamins and Hormones, 5,1 .

Morton, R. A., Cama, H. R., Dalvi, P. D., Field, A. C. \& Salah, M. K. (1950). Unpublished.

Morton, R. A. \& Creed, R. H. (1939). Biochem. F. 33, 318.

Morton, R. A., Salah, M. K. \& Stubbs, A. I. (1947). Nature, Lond., 159, 744.

Robeson, C. D. \& Baxter, J. G. (1947). F. Amer. chem. Soc. 69, 136.

Shantz, E. M. (1950). F. biol. Chem. 182, 515.

Shantz, E. M. \& Brinkman, J. H. (1950). F. biol. Chem. 183, 467.

Shantz, E. M., Embree, N. D., Hodge, H. C. \& Willis, J. H. (1946). F. biol. Chem. 163, 455.

Sharman, I. M. (1949). Brit. F. Nutrit. 3, viii.

Underhill, S. W. F. \& Coward, K. H. (1939). Biochem. Y. 33, 589.

von Euler, H. Demole, V., Karrer, P. \& Walker, O. (1930). Helv. chim. Acta, 13, ro78.

von Euler, H., Karrer, P., Hellström, H. \& Rydbom, M. (1931). Helv. chim. Acta, 14, 839.

von Euler, H., Karrer, P. \& Solmssen, U. (1938). Helv. chim. Acta, 21, 2 I 1.

von Euler, H., Karrer, P. \& Zubrys, A. (1934). Helv. chim. Acta, 17, 24.

Wilkinson, H. (1 941). Biochem. F. 35, 824.

Zechmeister, I.. (1944). Chem. Rev. 34, 267.

Zechmeister, L. (x949). Vitamins and Hormones, 7, 59.

\title{
Vitamins $\mathrm{A}$ and Vision
}

\section{By R. A. MoRTon, Department of Biochemistry, University of Liverpool}

According to the ideas now current, the following sequence obtains in the formation of visual purple: ( $\mathrm{I}$ ) The animal ingests carotenoid provitamins, and sometimes preformed vitamin $\mathrm{A}$, but absorption of unchanged carotenoids is small or very small indeed, depending on the species. (2) An enzyme system (carotenase?) operating in the gut wall results in fission of the $C_{40}$ molecules to $C_{20}$ molecules and vitamin $A$ aldehyde is formed, to be rapidly reduced to free vitamin A. (3) Much of the vitamin A is esterified in the gut wall and then transported to the liver to be stored largely as ester in the Kupffer cells. Either in the true liver cells, or in the blood plasma, or in both, an esterase acts on the vitamin, and the outcome is a fairly constant plasma level of the order of $\mathrm{I}$ i.u. $(0.3 \mu \mathrm{g}$.) free vitamin A per ml. (4) A small but fairly constant amount of vitamin $A$ is found in the pigment epithelium readily accessible to the retina. (5) In the process of dark adaptation the reddish pigment, rhodopsin (visual purple), accumulates in the rods of the retina, but the process is delayed when the blood level of vitamin $\mathrm{A}$ is low; there is then defective scotopic vision, that is to say vision in light of low intensity. (6) Exposure to bright light results in decomposition of rhodopsin in vivo but the pigment is regenerated in the dark. (7) In some freshwater fishes and amphibia rhodopsin is replaced by porphyropsin and vitamin $A_{1}$ by vitamin $A_{2}$. The latter differs from the former in having one additional conjugated double bond in the substituted six-membered ring. (8) Photopic vision, which is vision in light of high 
intensity, differs from scotopic vision in that there is discrimination of colour as well as of brightness. The physiological observations requiring chemical interpretation are much more complicated in photopic vision than in scotopic vision but as yet no key substance other than vitamin A can be suggested.

\section{Rhodopsin and porphyropsin}

The rods in the retina of the vertebrate eye are composed of inner and outer segments. The outer limb is easily detached mechanically, and although it has no nucleus it is rich in rhodopsin. Suitably treated rod suspensions yield solutions of rhodopsin in $\mathrm{I} \%$ aqueous digitonin. Rhodopsin is a conjugated protein and according to one careful experiment its molecular weight is near 270,000 . In solution its absorption curve shows $\lambda_{\max .} 500 \mathrm{~m} \mu$., with weaker selective absorption near $340-35^{\circ} \mathrm{m} \mu$., and stronger selective absorption near $275 \mathrm{~m} \mu$. due to aromatic acids in the protein. For porphyropsin, which in some fish and amphibian eyes plays the same part as rhodopsin, $\lambda_{\max }$ occurs near $522 \mathrm{~m} \mu$.

In isolated retinas, the final product obtained after exposure to light is vitamin $A_{1}$ from rhodopsin and vitamin $A_{2}$ from porphyropsin. The process can occur also in solutions of rhodopsin which have not been treated with alum, and in a cell-free brei from ox retinas. Exposure to light of preparations of rod outer segments, or of rhodopsin solutions prepared therefrom, results not in vitamin $A_{1}$ or $A_{2}$ but in retinene $e_{1}$ or retinene $_{2}$. If, however, the rod outer segments are suspended in a watery extract of retinas, vitamin A can again be formed as a result of irradiation with visible light.

\section{Retinene $_{1}$ and retinene 2}

These two substances, derived photochemically from the prosthetic groupings of rhodopsin and porphyropsin, respectively, may be extracted by means of chloroform. 'They are characterized by absorption maxima in chloroform at 385 and $405 \mathrm{~m} \mu$. respectively (cf. vitamin $A_{1} 326 \mathrm{~m} \mu$, vitamin $A_{2} 350$ and $286 \mathrm{~m} \mu$.). With the antimonytrichloride reagent $\left(\mathrm{SbCl}_{3}\right.$ in $\left.\mathrm{CHCl}_{3}\right)$ they show blue-green colours with $\lambda_{\text {max. }} 664$ and $705 \mathrm{~m} \mu$. respectively (cf. vitamin $A_{1} 620 \mathrm{~m} \mu$., vitamin $A_{2} 695 \mathrm{~m} \mu$.). The amounts of them obtainable from retinas are exceedingly small, and only their very high molecular extinction coefficients account for their spectroscopic detection in such low concentration. Controlled oxidation of vitamins $A_{1}$ and $A_{2}$ yields the corresponding aldehydes $\mathrm{C}_{20} \mathrm{H}_{28} \mathrm{O}$ and $\mathrm{C}_{20} \mathrm{H}_{28} \mathrm{O}$. Both have been obtained pure and crystalline, and show the properties of retinene ${ }_{1}$ and retinene $e_{2}$ respectively. By the Oppenauer reaction, retinene ${ }_{1}$ has been obtained from vitamin $A_{1}$, and under certain conditions a substance $C_{20} H_{26} O$, isomeric with retinene ${ }_{2}$ and very closely resembling it, appears instead.

The conversion of vitamin $A$ aldehyde to vitamin $A$ is a reversible process involving a retinene reductase, vitamin $A$ dehydrogenase. The apo-enzyme extracted from cattle retinas works equally well on the two aldehydes; it requires coenzyme $\mathrm{I}$. The hydrogen donor used experimentally was fructose $1: 6$-diphosphate which presumably is first split to yield 3 -glyceraldehyde phosphate. 


\section{Photochemistry of rhodopsin}

The initial photochemical change in the bleaching of rhodopsin by light is followed by a series of reactions in the dark. The latter can be greatly delayed if the irradiation is carried out at quite low temperature. At $-78^{\circ}$ an orange-coloured substance, transient orange, is formed $\left(\lambda_{\max .} c .490 \mathrm{~m} \mu\right.$.), but on warming to room temperature indicator yellow is formed, and this is the immediate precursor of retinene ${ }_{1}$.

Vitamin $A$ aldehyde prepared in vitro combines with many amines (e.g. $\mathrm{CH}_{3} \mathrm{NH}_{2}$ ), amino-acids and proteins to yield solutions with $\lambda_{\max .} 3^{65} \mathrm{~m} \mu$. in alkaline media, and $440 \mathrm{~m} \mu$. in acid media. These maxima agree with those of natural indicator yellow and the absorption curves are entirely analogous to those of indicator yellow.

Solutions of rhodopsin prepared in a dim red light may be frozen at $-78^{\circ}$ and thereupon exposed to intense white light. The pink solid then becomes orange in colour. The material is then allowed to come to equilibrium at room temperature in the dark (about I hr.). Almost exactly half the original absorption at $500 \mathrm{~m} \mu$. is restored and about half the maximum amount of indicator yellow is formed. For the regenerated rhodopsin (isorhodopsin) $\lambda_{\max }$ is slightly, but definitely, below $500 \mathrm{~m} \mu$.

The irradiation at $-78^{\circ}$ is now repeated and a second regeneration at room temperature is allowed to take place. Again the amount of indicator yellow increases and the absorption of the regenerated 'isorhodopsin' falls by half to $25 \%$ of the original. The whole process may be repeated several times, and the value of $\lambda_{\text {max }}$ remains constant at $492 \mathrm{~m} \mu$. for the regenerated material. At intermediate temperatures $\left(-45^{\circ},-15^{\circ}\right.$ etc.) rather more complicated results are obtained:

$$
\begin{aligned}
& \text { Rhodopsin } \stackrel{-30^{\circ}}{\longrightarrow} \text { lumirhodopsin } \stackrel{-15^{\circ}}{\longrightarrow} \text { metarhodopsin (transient orange?). } \\
& \text { Two metarhodopsin } \underset{\text { darkness (indicator yellow) }}{23^{\circ}} \text { retinene-protein + rhodopsin. }
\end{aligned}
$$

The whole process is perhaps as follows:

Rhodopsin $+n h \nu \rightarrow$ transient orange.

Two transient orange $\rightarrow$ indicator yellow $+i$ sorhodopsin.

isorhodopsin $+n \mathbf{h} \nu \rightarrow$ transient orange.

Two transient orange $\rightarrow$ etc.

It is clear that to account for the fact that materials absorbing selectively near $500 \mathrm{~m} \mu$. are obtained from retinene, it is necessary to invoke either the action of free radicals or of compounds in which two $\mathrm{C}_{20}$ molecules are attached so as to maintain conjugation. Structures consistent with the properties of rhodopsin, transient orange, and indicator yellow have been put forward.

There are weighty reasons for thinking that in normal scotopic vision the act of absorbing light results in electron transfer along the chain of conjugated double bonds to the retinal end-organ, and that bleaching by light is not necessarily a normal and integral part of the perception of dim light. The photochemistry, which is a key to investigation, may not reproduce any physiological process except near the threshold between scotopic and photopic vision. 


\section{Photopic vision}

'The scotopic sensitivity curve with $\lambda_{\max } 500 \mathrm{~m} \mu$. agrees well with the absorption spectrum of rhodopsin. The photopic action spectrum with $\lambda_{\max } .560 \mathrm{~m} \mu$. has been taken to imply the existence of iodopsin analogous to rhodopsin. The electrophysiological studies of Granit reveal action spectra corresponding with his concept of dominators and modulators. A dominator is a sensory mechanism, scotopic or photopic, characterized by a broad sensitivity curve extending over a wide range of wave-lengths; the difference between the principal dominators accounts for the Purkinje shift. Modulators have a much narrower response curve and their action spectra fall into groups situated in three spectral regions, $440-470,520-540$ and $580-600 \mathrm{~m} \mu$. There is also a modulator near $500 \mathrm{~m} \mu$. Their narrow action spectra make the modulators peculiarly suitable as mediators of colour vision.

There is at present great activity in the study of colour vision, and it is very difficult for chemists to decide which physiological observations are likely to provide 'labels' for chemical substances and which are not. Thus iodopsin may be as distinct a substance as rhodopsin or it may correspond with the summation of the absorption spectra of three or more modulators.

The modulators with their narrow-banded action spectra bear a certain resemblance to the unstable absorbing entities present in the chloroform solutions of the product of the antimony-trichloride reaction. A vast excess of antimony trichloride is necessary to ensure the stability of the colours, and even then it is not great. The two narrow bands for vitamin $A_{1}\left(620 \mathrm{~m} \mu\right.$.) and retinene ${ }_{1}(664 \mathrm{~m} \mu$.) are both accompanied by satellite absorption.

Vitamins $A_{1}$ and $A_{2}$ and the retinenes give rise to coloured solutions with concentrated sulphuric or phosphoric acid. The absorption spectra of such solutions exhibit narrow bands with maxima agreeing fairly closely with those of Granit's modulators. The existence of these modulator analogues makes it necessary to explore the possibility that photopic as well as scotopic vision requires vitamin $A$ as an indispensable part of the chemical system.

Attempts to prove the existence of iodopsin as an independent entity have not been successful enough to compel assent, but both Wald and Bliss have provided indirect evidence for the presence of such a pigment in the cones. The material is not very stable but it seems clear enough that it can produce retinene. Nevertheless, it is not yet proved that retinene and vitamin A have a central position in photopic vision, but there is no other working hypothesis.

The biological activity of vitamin A depends in the last resort on the chain of conjugated double bonds from which derive $(a)$ electron mobility, $(b)$ ease in effecting the change in vivo of $\mathrm{RCH}_{2} \mathrm{OH} \rightleftharpoons \mathrm{RCHO}$, and $(c)$ ready reactivity of the - $\mathrm{CHO}$ group with $\mathrm{NH}_{2}$ or other groups in proteins.

Many questions remain unanswered, such as the nature of the collection of enzymes in the rod outer segments, the chemical constitution of rhodopsin, whether, for instance, it contains phospholipins and nucleoproteins, the mechanism of stabilizing visual pigments, and the role of trace metals in eye tissues. 
The evolutionary significance of the change from porphyropsin to rhodopsin, which occurs in some species of amphibia on metamorphosis, is an important and most interesting field of investigation.

\title{
REFERENCES
}

A full list of references to original papers on which the above summary is based would occupy much space. Most of the earlier work is referred to by Morton (Rep. Progr. Chem. 1950, 46, 244). R. Granit (Annu. Rev. Physiol. 1950, 12, 485) reviews recent work on the physiology of vision, and G. Wald (Biochim. Biophys. Acta, 1950, 4, 215) discusses the interconversion of the retinenes and vitamins A in vitro. The following refer to the most recent work:

Bliss, A. F. (1949). Biol. Bull. Woods Hole, 97, 221.

Collins, F. D. \& Morton, R. A. (1950). Biochem. F. 47, 3.

Collins, F. D. \& Morton, R. A. (1950). Biochem. F. 47, 10.

Collins, F. D. \& Morton, R. A. (1950). Biochem. F. 47, I8.

Wald, G., Durell, J. \& St George, R. C. C. (1950). Science, III, 179.

Wald, G. \& Hubbard, R. (1950). Proc. nat. Acad. Sci., Wash., 36, 92.

\section{Standardization and Requirement of Vitamin $\mathbf{A}$}

\author{
By E. M. Hume, Lister Institute of Preventive Medicine, London S.W. I
}

\section{Introduction}

The standardization of vitamin $\mathrm{A}$ and the requirement for vitamin $\mathrm{A}$ are two subjects not very closely allied but they have both received special attention from the Vitamin A Subcommittee of the Medical Research Council's Accessory Food Factors Committee of which I have been the Secretary ever since it was first set up to deal with the standardization of vitamin A. Most of what is now said refers to the joint work of the members of that Subcommittee. There are two stories to be told and both are longer than there is space for, so only that of standardization will be told in full.

It was in I93 I that the Health Organization of the League of Nations held its first conference, aimed at setting up international standards for certain of the vitamins, for at that time there were no methods except biological methods for testing any of the then known vitamins. It was essential to set up standard substances to act as stable yardsticks against which materials could be tested for their potency and to define a fixed amount of the standard substance whose unchanging activity should be the international unit.

\section{Standardization}

\section{Establishment of the carotene standard}

At this first conference carotene was set up as international standard for vitamin A, and it retained this position, not unassailed, until 1949 (Permanent Commission on Biological Standardization: League of Nations, 1931). Indeed it has long been under heavy criticism, mainly on the fundamental ground that it is not vitamin A. Such a criticism had at first little sense, because no satisfactory form of vitamin A itself was available, but by 1939 pure esters of vitamin $A$ had been prepared, and the stage was all set to propose vitamin $\mathrm{A} \beta$-naphthoate as international standard. These plans were 